\title{
O CAPITAL DA ESPERANÇA: A EXPERIÊNCIA DOS TRABALHADORES NA CONSTRUÇÃO CIVIL DE BRASÍLIA
}

\author{
Gustavo Lins Ribeiro \\ Editora Universidade de Brasília, 2008, 276 p.
}

Este livro é o resultado de uma pesquisa para uma dissertação de mestrado defendida na Universidade de Brasília em 1980, publicada apenas trinta anos depois. De sua leitura percebe-se ainda a vitalidade dos anos 1970, quando se buscava o olhar alternativo das classes subalternas sobre a história, oculto pelo discurso triunfalista da ideologia desenvolvimentista, seja aquele do populismo dos anos 1950, ou do autoritarismo do regime militar dos anos 1970. Este olhar se percebe na ironia do título: o verdadeiro "capital" que ergueu a utópica Brasília é explicitado no resgate da memória dos migrantes, trabalhadores da construção civil, na construção da Capital Federal. Assim, o livro se empenha em dissecar as entranhas do projeto subjacente da modernização conservadora, ao estudar uma forma específica de produção, o "grande projeto", como totalidade complexa e contraditória em que exploração capitalista predatória e o ufanismo nacionalista buscam se conciliar.

$\mathrm{Na}$ introdução do livro, a construção de Brasília é apresentada como um caso paradigmático dessa "forma de produção". Seria, ao mesmo tempo, a concretização de um grande projeto de construção civil e a expressão mais acabada da realização de um projeto político e ideológico. Como "forma de produção", o grande projeto reúne um conjunto de especificidades que se articulam de maneira recorrente, criando um perfil de atividade produtiva típica da construção de hidrelétricas, rodovias, entre outros. Geralmente ocorrem em áreas isoladas, a partir de decisões que envolvem grandes empresas de construção e uma presença forte do Estado. Um grande projeto cria, por um período determinado, um "enclave", atraindo um aglomerado de trabalhadores vivendo um cotidiano restrito, marcado pelo trabalho e controlado pelas companhias, num território delimitado. Um fator fundamental sempre presente é a criação de uma dinâmica migratória atraindo trabalhadores no momento em que se inicia 
e, repentinamente, os expulsando, quando a obra se conclui. É uma mão de obra migrante reunida sob condições excepcionais (homens sem família, numa intensa atividade produtiva, sem opções de lazer), caracterizando o espaço produtivo por uma estreita conjugação entre trabalho e habitação. Sendo uma modalidade de produção própria da construção civil, o grande projeto que levou ao erguimento da nova capital, mais do que qualquer hidrelétrica, usina ou estrada, contou com um esforço mais intenso de justificação ideológica. Esse discurso ideológico, mais do que outros, busca inspiração quase mítica no "bandeirantismo", assim como nos símbolos recorrentes da construção da nacionalidade, como a "Primeira Missa", "a Marcha para o Oeste", a "Independência", para justificar a busca constante de interiorização do capital e ocupação do território nacional. Ao lado disso, sendo um símbolo do progresso do país e da afirmação ufanista da nacionalidade, a sua construção, em menos de quatro anos, serviu também para ocultar e justificar a enorme exploração dos trabalhadores. Temos, então, o objetivo a que o livro se propõe: diante da necessidade de "desvendar as construções ideológicas existentes sobre o tema", visa "pensar Brasília mais além da mitologia que a recobriu". A introdução, a partir da recuperação da literatura então existente, frente ao discurso triunfalista predominante, aponta para contradições como "a ausência dos operários no espaço urbano do Plano Piloto", ou para a ambiguidade jurídica criada pelo território da obra, em que se impunha a autoridade da empresa pública como a Companhia Urbanizadora da Nova Capital (NOVACAP), no lugar do Estado.

O livro, assim, procura abarcar o funcionamento do grande projeto a partir do ponto de vista dos trabalhadores que nele se empenharam. Dentro dessa perspectiva, o primeiro capítulo, "os trabalhadores", traça um perfil dos principais protagonistas da realização da construção de Brasília. Na caracterização do operariado, parte-se de sua relação com a organização do território da construção, e as diferentes modalidades de subordinação frente aos entes que o controlavam: seja a NOVACAP e a Candangolândia, de caráter estatal; as várias companhias com seus acampamentos e canteiros de obras; ou a "Cidade Livre", espaço reservado ao comércio e a pensões para trabalhadores desvinculados de construtoras. O controle do território se estende ao controle do fluxo de trabalhadores, à gestão de sua chegada, seu recrutamento e seleção. A um "fluxo desorganizado", num momento inicial, se sucedeu, rapidamente, a implantação de um quadro institucional para tornar o "fluxo organizado". A política de gestão da migração foi fundamental para a instalação do grande projeto, através da NOVACAP e do Instituto Nacional de Imigração e Colonização (INIC). 
Gestão da migração e seleção de trabalhadores garantiam o tipo ideal de trabalhador requisitado: jovem, com saúde, sem família e, se possível, com qualificação profissional. Apesar do rigor do controle do fluxo e triagem dos trabalhadores, criou-se uma forte pressão populacional com a chegada de migrantes, às vezes com família, produzindo vários casos de ocupação de terras. Por outro lado, essa política migratória gerou distorções no perfil da população residente: jovem, masculina, sem família, em função unicamente do trabalho. Enfim, era uma população marcada pela provisoriedade de sua implantação. A ausência relativa de mulheres ou de famílias, a falta de tempo livre, a promiscuidade na "cidade livre", o peso social da zona de meretrício, a exacerbação da exploração do trabalho, a má habitação, entre outros aspectos, marcavam a precariedade do cotidiano. Nesse contexto, é no interior das companhias e na estruturação das relações de produção que surgem as formas de diferenciação social entre os trabalhadores, por meio de um sistema de relações pessoais e favorecimentos. Nos poucos momentos de lazer, nos espaços de informalidade, uma forma de diferenciação mais espontânea é a de sua origem regional (como mineiros, baianos, goianos...), apontando para a condição de migrante como base essencial para o seu reconhecimento social e, principalmente, para a reconstituição de suas redes sociais.

O segundo capítulo, "o acampamento", analisa outro traço fundamental do seu cotidiano: o modo como foi resolvida a questão de sua habitação provisória. A questão crucial era prover habitação para milhares de trabalhadores sem família, de modo a não dispersá-los pelo território, concentrá-los em lugares próximos da construção, para que estivessem disponíveis ao processo produtivo. A estruturação do acampamento, de um lado, revela a hierarquia de autoridade e de funções no interior da empresa, e, de outro, permite uma organização do cotidiano que facilite o desempenho da atividade produtiva. Dessa maneira, todo o cotidiano dos trabalhadores está condicionado pelo funcionamento e administração do acampamento. Da análise de um modelo de acampamento, o autor passa a uma reflexão interessante, apoiado nos estudos de Goffmann, no sentido de responder à pergunta: o acampamento, no contexto de um grande projeto, é uma instituição total? Ele tenta caracterizar a experiência do acampamento num grande projeto como uma forma de "experiência provisória de instituição total". O certo é que, no acampamento, manifestase o que seria a condição existencial do migrante, sem alternativa senão a de se submeter a esse regime: a de estar sempre disponível para o trabalho.

Esta é, inclusive, uma das conclusões que se poderia tirar da leitura do terceiro capítulo, sobre "o trabalho". Tudo, no contexto do grande 
projeto, leva a que a vivência do migrante se resuma a um trabalho constante e intenso. O livro registra a exacerbação das formas mais comuns de exploração na construção civil, como a prática incorporada das horas extras, a sobreposição de jornadas de trabalho nas "viradas" e a intensificação de seu ritmo através do mecanismo das "tarefas". O cotidiano era de tal modo dominado pelo trabalho que se chegava a uma homogeneização entre a noite e o dia, redefinindo o tempo social e individual. Foi assim que a construção da "obra do século" foi decantada como o "ritmo Brasília". Trechos de depoimentos de antigos operários descrevem em detalhes o modo como se organizava essa atividade produtiva, marcada por frequentes "viradas" e "tarefas". O grande estímulo para que se submetessem a tal situação de exploração foi analisado sob a figura do "fetichismo do salário": rememorado como um tempo de trabalho excessivo, mas também como uma oportunidade em que se ganhava muito dinheiro. Outros mecanismos ideológicos também eram acionados, como as visitas institucionais nas quais se destacava a presença pessoal do Presidente da República, Juscelino Kubitschek. Havia, por fim, a situação de ambiguidade jurídica que, por um lado, justificava o poder de Estado exercido pela NOVACAP, garantindo a ordem e permitindo esse ritmo de construção, e por outro, a ausência de órgãos para mediar os conflitos entre trabalho e capital, e fiscalizar as condições de vida dos trabalhadores.

O quarto capítulo, "os conflitos", reúne três âmbitos em que se desenvolve uma crise latente em torno das condições de vida desses trabalhadores: o lazer, a alimentação e a habitação. Percebe-se como, de um âmbito a outro, aumentam a gravidade dos conflitos, sua difusão social e potencialidade de agregação coletiva, até a criação de formas de representação e pressão propriamente políticas. Surgem, também, traços da condição migrante de sua população, sinalizando como será sua presença futura, em Brasília e em outras regiões. A questão do lazer remete à ausência de tempo livre e à condição da maioria dos migrantes como homens sós, sem família, impactando sua estrutura pessoal e trajetória de vida. Com efeito, os conflitos giravam em torno dos contatos com a zona de prostituição e o consumo excessivo de bebidas alcoólicas, normalmente proibidas nos acampamentos. Os casos de brigas ocasionados por prostitutas e embriaguez não criavam solidariedade entre os trabalhadores, e como comportamento moralmente reprovável, levavam ao seu isolamento. Entre trecheiros, em estudos posteriores, percebe-se como o rompimento com a família, proporcionado pelo sistema de "grande projeto", pelo trabalho temporário em grandes lavouras ou na construção 
civil, dificulta sua reinserção social, sendo uma característica marcante a dependência da bebida. Já o âmbito da alimentação remete diretamente às condições predatórias em que ocorre a exploração do trabalho num grande projeto. Os conflitos ocorriam, geralmente, no interior das cantinas dos acampamentos, cujo papel fundamental era alimentar a força de trabalho. Porém, como terceirizadas, elas deviam se submeter às necessidades produtivas da empresa, e ganhavam em função do barateamento dos custos da alimentação. Sendo os operários submetidos a um trabalho constante e excessivo, a má qualidade desse serviço degenerava facilmente em rebeliões. $\mathrm{O}$ autor faz um paralelo com a literatura da época sobre os "quebra-quebras" no sistema de transportes. Porém, sob o seu ponto de vista, como trabalhadores migrantes, pode-se supor que vivenciariam ali uma condição extrema de "humilhação social". O autor analisa também, longamente, um episódio marcante, o caso do massacre de 8 de dezembro de 1959, confrontando as versões dos trabalhadores (não oficial) e aquela que se veiculou na grande imprensa da época.

No entanto, é em torno do problema habitacional, que uma verdadeira organização coletiva de cunho político ganha forma. Um conflito latente, desde o início do grande projeto, surgiu diante da pretensão de manter os trabalhadores provisoriamente no território da obra. A pressão das migrações e a demanda por moradia permanente levou a situações de conflito em todo o território, ganhando uma configuração emblemática nos casos da Vila Sarah Kubitschek (que originou a futura cidade satélite de Taguatinga), da Vila Amaury (princípio do que seria Sobradinho) e da fixação do Núcleo Bandeirante, ou a antiga "cidade livre". Neles se exprimiam articulações políticas em busca de soluções para a demanda de fixação no território, antecipando a dinâmica socioespacial do futuro Distrito Federal. Nesses movimentos já se percebe a contraposição complementar entre o Plano Piloto e as cidades satélites. Uma primeira observação que cedo se impôs, também sobre sua posterior articulação política, foi a relação entre uma população migrante implantada provisoriamente e sua demanda por fixação no território. Nela se percebe, justamente, o anseio por sair da condição migrante, encontrar casa, formar família, chegar à cidadania, o que era legitimado pelo próprio discurso sobre a construção da capital federal. A única luta política organizada, que emergiu naquele período histórico, implicitamente reivindicava a saída da condição migratória, a de não ser mais alguém unicamente voltado para o trabalho. Outra observação deriva da própria história posterior do Distrito Federal, em que a questão da migração e habitação permaneceu em pauta, com outra variante política. Se na época da construção os migrantes eram 
vistos como um sinal de progresso, de trabalhadores mobilizados em torno de um projeto de nacionalidade, na verdade, eles estavam no bojo de um processo que transformava uma sociedade rural em urbana, polarizada entre centros modernos de classe média e periferias em que vivem os trabalhadores em situação precária. Nos anos 1990, o Distrito Federal foi a Região Metropolitana que mais se expandiu recebendo migrantes, extravasando, inclusive, para localidades do entorno em Goiás, muito em função de uma política clientelista de cunho populista. Seria interessante cotejar este trabalho com o desenvolvimento urbano recente, relacionando migrantes, habitação e espaço urbano.

Este trabalho, ao mesmo tempo antropológico, histórico e investigativo, procurando descortinar a verdadeira história do desenvolvimento brasileiro, mostra uma riqueza de detalhes sugerindo pistas para um entendimento mais amplo, não só das migrações, mas também dos meandros da estruturação da sociedade brasileira. Nesse sentido, a riqueza das fotos documentais sobre o período da construção, o uso frequente e intensivo de mapas e croquis para o estudo da dinâmica socioespacial do grande projeto, a análise detalhada de casos, ajudam a compreender como viviam, efetivamente, os migrantes em seu cotidiano, e confirmam o rigor com que foi feita a pesquisa. Demonstram, assim, o desejo de trazer à luz uma história que corre o risco de cair no esquecimento.

Sidnei Marco Dornelas Assessor Setor Pastoral da Mobilidade Humana - CNBB 